\title{
Support for healthy eating at schools according to the comprehensive school health framework: evaluation during the early years of the Ontario School Food and Beverage Policy implementation
}

\section{Taryn Orava, PhD (1); Steve Manske, EdD (2); Rhona Hanning, PhD (1)}

This article has been peer reviewed.

\begin{abstract}
Introduction: Provincial, national and international public health agencies recognize the importance of school nutrition policies that help create healthful environments aligned with healthy eating recommendations for youth. School-wide support for healthy living within the pillars of the comprehensive school health (CSH) framework (social and physical environments; teaching and learning; healthy school policy; and partnerships and services) has been positively associated with fostering improvements to student health behaviours. This study used the CSH framework to classify, compare and describe school support for healthy eating during the implementation of the Ontario School Food and Beverage Policy (P/PM 150).
\end{abstract}

Methods: We collected data from consenting elementary and secondary schools in a populous region of Ontario in Time I (2012/13) and Time II (2014). Representatives from the schools completed the Healthy School Planner survey and a food environmental scan (FES), which underwent scoring and content analyses. Each school's support for healthy eating was classified as either "initiation," "action" or "maintenance" along the Healthy School Continuum in both time periods, and as "high/increased," "moderate" or "low/decreased" within individual CSH pillars from Time I to Time II.

Results: Twenty-five school representatives (8 elementary, 17 secondary) participated. Most schools remained in the "action" category $(\mathrm{n}=20)$ across both time periods, with varying levels of support in the CSH pillars. The physical environment was best supported (100\% high/increased support) and the social environment was the least (68\% low/decreased support). Only two schools achieved the highest rating (maintenance) in Time II. Supports aligned with P/PM 150 were reportedly influenced by administration buy-in, stakeholder support and relevancy to local context.

Conclusion: Further assistance is required to sustain comprehensive support for healthy eating in Ontario school food environments.

Keywords: schools, nutrition policy, school health, food environment, comprehensive school health

\section{Introduction}

The school environment can facilitate the development of positive, healthy living behaviours in children during their formative years. ${ }^{1-3}$ As the high prevalence of childhood obesity continues, schools have been encouraged to adopt policies that formally promote healthy eating behaviours among students. ${ }^{4-6}$ Internationally, school nutrition policies have played a critical role in supporting the healthy eating behaviours of children. ${ }^{7-9}$ In 2011, following the implementation of school

\section{Highlights}

- Results from the Healthy School Planner classified most schools as "action" along the Healthy School Continuum. This suggests the presence of modest support for healthy eating, with room for improvement.

- The physical and social environments pillar was divided to examine the unique attributes within each environment type. The physical environment was well supported, with safe, clean spaces for students to eat. In the social environment pillar, healthy eating was not often highly valued, with few schools identifying healthy eating to be a "very high" $(16 \%)$ or "high" (8\%) priority.

- Programs and practices within the teaching and learning, partnerships and services and healthy school policy pillars required further buy-in from school administrators, additional funding and deeper engagement with school stakeholders.

nutrition policies in several Canadian provinces and territories, the province of Ontario mandated the School Food and Beverage Policy (Policy/Program Memorandum No. 150 [P/PM 150]) as a set of nutritional standards applied to foods and beverages offered for sale in school food venues, at school events and through nutrition programs. ${ }^{10}$ 
The policy states that any school food venue must adhere to an $80 \%-20 \%$ rule. That is, of foods and beverages offered for sale, $80 \%$ or more must fall into the category "sell most," $20 \%$ or less into the category "sell less" and $0 \%$ into the category "not permitted for sale." 10 These P/PM 150 food categories are determined by fat, sugar, sodium, caffeine and/or calcium levels within specified categories of foods and beverages. ${ }^{10}$ Schools are responsible for the implementation and ongoing monitoring of the $80 \%-20 \%$ rule, with up to 10 exemption days in each school year when even "not permitted" foods may be offered for sale. ${ }^{10}$ Preliminary studies indicate that some school stakeholders have encountered difficulties implementing P/PM 150 , thereby limiting the ability of schools to reach full policy compliance. ${ }^{11-13}$ These findings are consistent with reports that nutrition policy adherence typically takes years. $^{14,15}$

Policies can falter when the local context is unsupportive of the change (e.g. the policy does not meet the current needs of the target population, or individuals responsible for implementation are unsupportive or unwilling to change).$^{7-9}$ Moreover, there is evidence that health policy implementation is most effective when it is combined with other approaches to facilitate healthy behaviours in children. ${ }^{16,17}$ The comprehensive school health (CSH) framework, for example, was informed by a social ecological approach, recognizing that in supporting positive student health behaviours, attention to school environments, teaching and learning and partnerships and services complements policy. ${ }^{7-9,18-23}$ Such multidimensional approaches to school health, also called "health-promoting schools" and "coordinated school health" approaches, are intended to support the health and academic achievement of students. ${ }^{24}$ The CSH framework is a model that examines the school environment using four interrelated pillars, defined in Table 1. Note that social and physical environments are combined in the model but are often observed and measured separately.

As P/PM 150 was mandated without a corresponding comprehensive implementation strategy, it is unknown how, or in fact whether, the school social and physical environments, teaching and learning, healthy school policy and partnerships and services pillars are working together in Ontario to support healthy eating.

TABLE 1

Comprehensive School Health pillars ${ }^{24,25}$

\begin{tabular}{|c|c|}
\hline Pillars & Definition \\
\hline \multirow{2}{*}{$\begin{array}{l}\text { Social and } \\
\text { physical } \\
\text { environments }\end{array}$} & $\begin{array}{l}\text { The social environment includes: } \\
\text { - the quality of the relationships among and between staff and students } \\
\text { in the school } \\
\text { - the emotional well-being of students } \\
\text { - relationships with families and the wider community } \\
\text { - support of the school community in making healthy choices by building } \\
\text { competence, autonomy and connectedness }\end{array}$ \\
\hline & $\begin{array}{l}\text { The physical environment includes: } \\
\text { - the buildings, grounds, play space, and equipment in and surrounding the } \\
\text { school } \\
\text { - basic amenities such as sanitation, air cleanliness and healthy foods } \\
\text { - spaces designed to promote student safety and connectedness and } \\
\text { minimize injury } \\
\text { - safe, accessible environments that support healthy choices for all members } \\
\text { of the school community }\end{array}$ \\
\hline \multirow[b]{2}{*}{$\begin{array}{l}\text { Teaching and } \\
\text { learning }\end{array}$} & $\begin{array}{l}\text { Teaching includes: } \\
\text { - formal and informal provincial/territorial curriculum, resources and associated } \\
\text { activities }\end{array}$ \\
\hline & $\begin{array}{l}\text { Learning includes: } \\
\text { - knowledge, understanding and skills for students to improve their health and } \\
\text { well-being and thereby enhance their learning outcomes } \\
\text { - professional development opportunities for staff related to health and } \\
\text { well-being }\end{array}$ \\
\hline $\begin{array}{l}\text { Healthy school } \\
\text { policy }\end{array}$ & $\begin{array}{l}\text { Policies, guidelines and practices that promote and support student well-being and } \\
\text { achievement and shape a respectful, welcoming and caring school environment for } \\
\text { all members of the school community }\end{array}$ \\
\hline \multirow[t]{2}{*}{$\begin{array}{l}\text { Partnerships } \\
\text { and services }\end{array}$} & $\begin{array}{l}\text { Partnerships include: } \\
\text { - the connections between the school and students' families } \\
\text { - supportive working relationships within schools (staff and students), between } \\
\text { schools, and between schools and other community organizations and } \\
\text { representative groups } \\
\text { - health, education and other sectors working together to advance school health }\end{array}$ \\
\hline & $\begin{array}{l}\text { Services include: } \\
\text { - community and school-based services that support and promote student and } \\
\text { staff health and well-being }\end{array}$ \\
\hline
\end{tabular}

Source: Adapted from Pan-Canadian Joint Consortium for School Health. The 4 Components of Comprehensive School Health [Internet]. Summerside (PE): The Joint Consortium for School Health; 2017 [cited 2014 Sep]. Available from: http://www.jcsh -cces.ca/index.php/about/comprehensive-school-health/4-pillars-explained

Therefore, using the CSH framework as a guide, our research aimed to (1) classify and compare the level of support for healthy eating within the CSH framework overall and for each CSH pillar across two time periods during the early years of P/PM 150 implementation; and (2) identify and describe the aspects of the school environment for which high levels of support were recorded and/or for which improvements were made within $\mathrm{CSH}$ pillars between the time periods we studied.
This research provided an opportunity to examine policy implementation in the context of broader supports for healthy eating over time in the naturalistic setting of schools in a large, diverse region of Ontario.

\section{Methods}

\section{Setting}

This research was conducted in a populous region of Ontario, Canada, in partnership 
with the local regional public health unit. The identity of the region and regional school boards is blinded in this article to protect the anonymity of participating schools. Data were collected from the two school boards (public and Catholic) at two times: Time I (April 2012 to June 2013) and Time II (December 2013 to June 2014). These time periods captured the early years of P/PM 150 implementation and were influenced by the political environment and restrictions placed on the timing for the recruitment of school staff in accordance with regional school board ethics review agreements. All aspects of this research received approval from the University of Waterloo Office of Research Ethics and the scientific review committees of participating school boards.

\section{Participants}

We recruited elementary and secondary schools for this study. We selected a random sample of 38 schools from all elementary schools $(\mathrm{N}=318)$ within participating school boards. Randomization was based upon geographic distribution across the three municipalities, school neighbourhood socioeconomic status, school population size, and equal representation between public and Catholic school boards. While rural schools were included, the study area is a predominantly urban region. All secondary schools in Ontario have on-site food venues offering daily service, while elementary schools offer limited (e.g. vending machines) or occasional (e.g. monthly specialty hot lunches) services. Therefore, secondary schools were considered more likely to be impacted by P/PM 150 standards, and all regional secondary schools $(\mathrm{N}=62)$ were invited to participate.

The principal from each participating elementary and secondary school was recruited through letters drafted by the authors and distributed by the regional school public health nurses (PHNs). A school representative was identified (either self-identified or selected by school administration) as being knowledgeable of healthy eating-related initiatives at their school. As this research took place over different school years, the representative changed in five cases from Time I to Time II.

\section{Instruments}

Consenting school representatives were asked to complete a paper and pencil version of the Healthy School Planner (HSP) survey and assist a university researcher with the on-site completion of a school food environmental scan (FES) checklist.

\section{Healthy School Planner (HSP) survey}

The HSP survey was developed by the Pan-Canadian Joint Consortium for School Health, and is a tool that can be used to classify a school's level of support for healthy eating, physical activity, tobacco control and/or positive mental health along the Healthy School Continuum (HSC) (Table 2) by asking 9 to 12 closedended indicator questions for each $\mathrm{CSH}$ pillar. ${ }^{25}$ The HSC rates schools within the "initiation," "action," or "maintenance" phase dependent on the level of support within the selected health topic. ${ }^{26}$ We selected the HSP survey's healthy eating module for this study as it directly corresponds to the pillars of the $\mathrm{CSH}$ framework. Questions in this module capture the presence and frequency of healthy eating-related programs (e.g. "Does your school offer cooking classes, gardening, trips to local farmer's markets?") and practices (e.g. "Does your school avoid the use of junk food as a reward through formal policies, informal practices, or not?"). Although no validation studies are available, the HSP has been acknowledged by the Health Council of Canada and Accreditation Canada as being sufficiently reliable and valid following revisions in $2009 .{ }^{27}$ Since the inception of our research study, the HSP survey has undergone reformatting and its scoring procedures have been revised. To strengthen consistency and comparability of findings, we opted to use the paper-based HSP survey, with corresponding $\mathrm{HSC}$, in both time periods. ${ }^{26}$ More information on the HSP is available at http://hsp.uwaterloo.ca.

\section{Food environmental scan (FES) checklist}

We developed the FES as an addendum to the HSP, which included 27 open- and closed-ended questions regarding the status of $\mathrm{P} / \mathrm{PM} 150$ implementation and healthy eating-related programs, practices and policies within each school. Prior to our study, the checklist had been pilot tested in secondary schools in a different region. ${ }^{28}$ The checklist included questions such as, "How many P/PM 150 exemption days has your school used and for what?"; and, "Are there opportunities for students to participate in gardening? If so, explain. If not, what barriers prevent such opportunities and what is needed to overcome these barriers?" We revised the FES checklist in Time II to include prompts to facilitate discussions led by the Time II data collector and additional questions to document changes to the school food environment since Time I (e.g. "Do you have the same cafeteria vendor as last year? If not, how does this vendor differ from last year's vendor?"). (A copy of the FES checklist is available from the corresponding author upon request.)

\section{Scoring and analysis}

\section{HSP survey scoring}

We scored each school's HSP using a three-step procedure, with outcomes compared across the two time periods. ${ }^{26}$

\section{Step 1: Scoring of CSH pillar indicator questions}

Responses to indicator questions were given a score of 1.0 (classified as "initiation”), 2.0 (classified as “action”), or 3.0 (classified as "maintenance”).

Step 2: Calculation of separate $\mathrm{CSH}$ pillar ratings We calculated the mean scores for pillar indicator questions. We gave each pillar a rating of initiation, action or maintenance based on the means (i.e. 1.0-1.99 = initiation; $2.00-2.80=$ action; and 2.81$3.00=$ maintenance) .

\section{Step 3: Calculation of an overall CSH rating}

We calculated the means across the five $\mathrm{CSH}$ pillar scores and assigned an overall
TABLE 2

The Healthy School Continuum ${ }^{25}$

\begin{tabular}{llll} 
& \multicolumn{1}{c}{ Initiation } & \multicolumn{1}{c}{ Action } & \multicolumn{1}{c}{ Maintenance } \\
\hline $\begin{array}{l}\text { Extent of meeting } \\
\text { recommendations }\end{array}$ & $\begin{array}{l}\text { Falls short of meeting } \\
\text { recommendations }\end{array}$ & $\begin{array}{l}\text { Meets some, but not all } \\
\text { recommendations }\end{array}$ & $\begin{array}{l}\text { Meets or exceeds } \\
\text { recommendations }\end{array}$ \\
$\begin{array}{l}\text { Recommendations } \\
\text { for the future }\end{array}$ & $\begin{array}{l}\text { Extensive room for } \\
\text { improvement }\end{array}$ & $\begin{array}{l}\text { Some room for } \\
\text { improvement }\end{array}$ & $\begin{array}{l}\text { Maintain current level } \\
\text { of commitment to } \\
\text { support healthy eating } \\
\text { at school }\end{array}$ \\
\hline
\end{tabular}


$\mathrm{CSH}$ rating along the HSC (i.e. 1.01.99 = initiation; $2.00-2.80=$ action; and $2.81-3.00=$ maintenance).

\section{Comparison over time}

We compared the overall ratings (i.e. initiation, action or maintenance) for Time I against those for Time II and classified them as "low/decreased," "moderate" or "high/increased” (Table 3). This classification was repeated for each separate $\mathrm{CSH}$ pillar.

\section{FES analysis}

We calculated descriptive statistics (mean, ranges) using SPSS Statistics software version 23 (IBM, Armonk, NY, USA). Openended questions (FES) underwent a deductive content analysis using NVivo qualitative analysis software version 10 (QSR International Pty Ltd., Melbourne, AUS) by which responses were grouped by $\mathrm{CSH}$ pillar and outcomes used to further describe the ordinal responses to the HSP indicator questions.

\section{Results}

\section{Study sample}

Of 82 schools invited to participate, 45 did participate in either Time I or Time II ( $55 \%$ response rate). However, only the 25 schools (8 elementary, 17 secondary) that completed an HSP survey in both time periods are included in the results. The HSP survey was completed by a combination of teachers (16 in Time I, 16 in Time II), principals or vice principals (11 in Time I, 15 in Time II), curriculum leads/department heads ( 3 in Time I, 4 in Time II), food service staff ( 1 in Time I, 1 in Time II), a school board representative ( 1 in Time I), and/or a PHN (1 in Time I, 1 in Time II).

\section{Overall rating along the Healthy Schools Continuum for Time I and Time II}

Figure 1 displays overall ratings along the Healthy Schools Continuum (HSC) at Time I and Time II. A majority of schools fell into the action stage along the HSC in Time I ( 6 elementary, 14 secondary) and Time II (6 elementary, 16 secondary). Very few achieved the highest rating of maintenance in either Time I (1 secondary) or Time II (2 elementary).

\section{Comparison of Time I versus Time II overall ratings}

As outlined in Figure 2, from Time I to Time II, three schools advanced along the
TABLE 3

Classification of schools' level of support for comprehensive school health from Time I (2012/13) to Time II (2014)

\begin{tabular}{|c|c|c|}
\hline $\begin{array}{l}\text { Change in the level of support } \\
\text { from Time I to Time II }\end{array}$ & Description & $\begin{array}{l}\text { Ratings along the Healthy } \\
\text { School Continuum } \\
\text { (Time I } \rightarrow \text { Time II) }\end{array}$ \\
\hline Low/decreased support & $\begin{array}{l}\text { From Time I to Time II schools } \\
\text { regressed along the HSC or } \\
\text { sustained the lowest rating of } \\
\text { "Initiation." }\end{array}$ & $\begin{array}{l}\text { Maintenance } \rightarrow \text { Action } \\
\text { Maintenance } \rightarrow \text { Initiation } \\
\text { Action } \rightarrow \text { Initiation } \\
\text { Initiation } \rightarrow \text { Initiation }\end{array}$ \\
\hline Moderate support & $\begin{array}{l}\text { From Time I to Time II schools } \\
\text { sustained a rating of "Action." }\end{array}$ & Action $\rightarrow$ Action \\
\hline High/increased support & $\begin{array}{l}\text { From Time I to Time II schools } \\
\text { improved along the HSC or } \\
\text { sustained the highest rating of } \\
\text { "Maintenance." }\end{array}$ & $\begin{array}{l}\text { Initiation } \rightarrow \text { Action } \\
\text { Initiation } \rightarrow \text { Maintenance } \\
\text { Action } \rightarrow \text { Maintenance } \\
\text { Maintenance } \rightarrow \text { Maintenance }\end{array}$ \\
\hline
\end{tabular}

a See Table 2.
HSC (one from initiation to action, two from initiation to maintenance); 20 schools remained within the action category, one school remained within initiation, and one school regressed (from maintenance to action). The movement along the HSC was dependent on the changes in the level of support for healthy eating within $\mathrm{CSH}$ pillars.

Extent of healthy eating support by CSH pillar Table 4 provides an overview of the schools' level of support for healthy eating within each of the CSH pillars from Time I to Time II. The sections below describe how healthy eating was supported, as outlined by the
$\mathrm{CSH}$ pillar indicator questions and responses to the FES.

Six schools (24\%) had an overall high/ increased rating of support for the social environment pillar, and many schools improved over the time periods. The indicators of support for healthy eating (retrieved from the HSP) were reported by few schools. These included self-report of a "high" (8\% of schools) or a "very high" (16\%) priority for healthy eating at their school; having a student food and nutrition council at the school (40\%); and hosting "nutrition month" activities $(36 \%)$. To encourage families to

\section{The social environment}

\section{FIGURE 1}

School ratings of support along the Healthy School Continuum in Time I (2012/13) and Time II (2014)

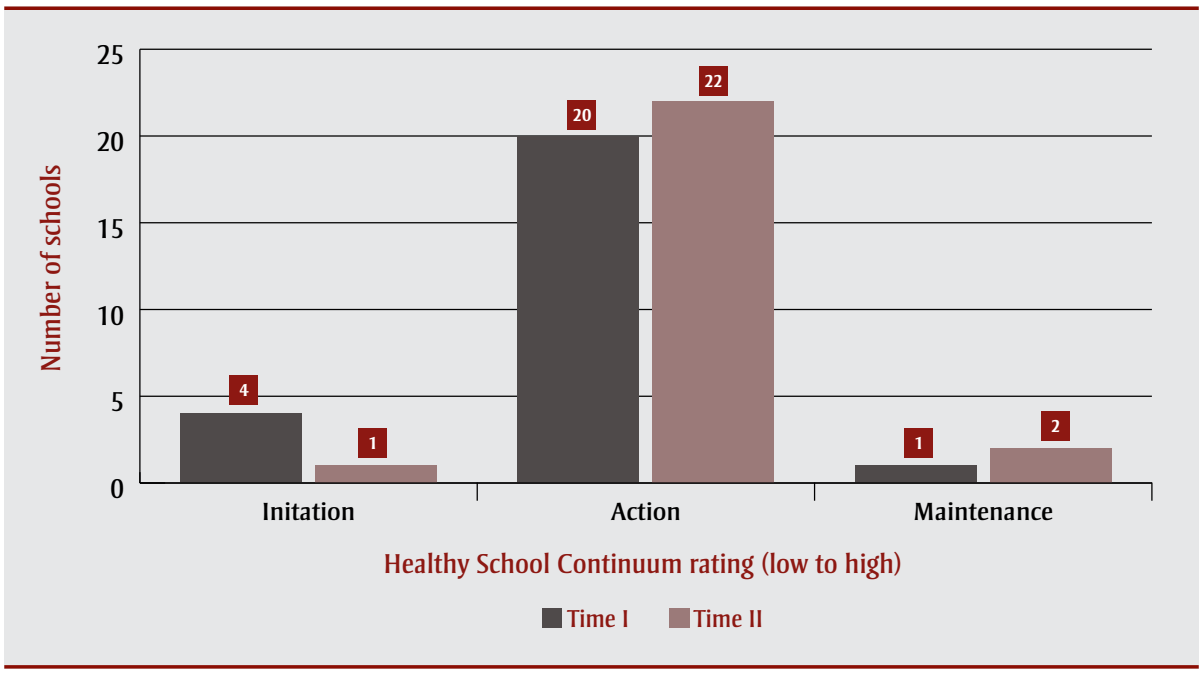


FIGURE 2

Overall movement of $\mathbf{2 5}$ elementary and secondary schools along the Healthy Schools Continuum ${ }^{a}$ between Time I (2012/13) and Time II (2014)

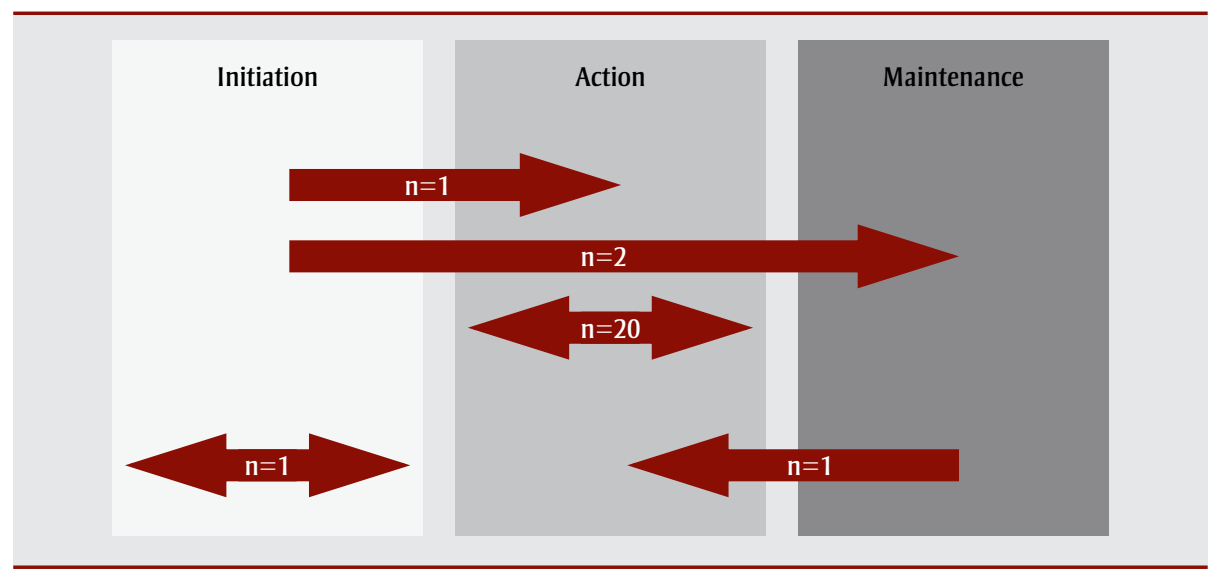

a See Table 2. reinforce healthy eating habits at home, schools most often distributed healthy snack and lunch suggestions (36\%) or Canada's Food Guide (16\%) to parents and families. Furthermore, to gather input on school-related healthy eating initiatives from the broader school community, schools reported collecting suggestions from students $(40 \%)$, parent organizations $(24 \%)$, parents and families (16\%) and staff (16\%).

\section{The physical environment}

The physical environment proved to be the $\mathrm{CSH}$ pillar that demonstrated the greatest support. All schools $(\mathrm{N}=25)$ in both time periods reported a high level of physical environment support for healthy eating (Table 4). Indicators of physical environment support included having an adequate number of tables and chairs for student meals, accessible drinking fountains and sinks for proper hand-hygiene. In addition, both elementary and secondary schools allowed enough time to eat lunch, socialize with friends and clean up (i.e. 20 minutes in elementary, 60-75 minutes in secondary).

All elementary and secondary schools promoted healthy eating to students throughout the school setting. Most often this was done through promotional posters (e.g. advertisements for local farmers' markets, nutrition month campaigns) or cafeteria signage in secondary schools (e.g. provincial seasonal fruit promotion cards, regional public health healthy eating stickers). Most secondary schools $(\mathrm{n}=15)$ also used student-designed murals and artwork to raise awareness and promote healthy food choices in cafeterias.
TABLE 4

Changes in level of support for healthy eating between Time I (2012/13) and Time II (2014) for 25 elementary and secondary schools, by comprehensive school health pillar

\begin{tabular}{|lccc|}
\multicolumn{1}{c}{ CSH pillar } & $\begin{array}{c}\text { Low/decreased } \\
\text { support from Time I } \\
\text { to Time II } \\
\# \text { of schools } \\
\mathbf{n ( \% )}\end{array}$ & $\begin{array}{c}\text { Moderate support } \\
\text { from Time I to Time II } \\
\text { \# of schools }\end{array}$ & $\begin{array}{c}\text { High/increased } \\
\text { support from Time I } \\
\text { to Time II } \\
\text { \# of schools }\end{array}$ \\
\hline $\begin{array}{l}\text { The social environment } \\
\text { The physical } \\
\text { environment }\end{array}$ & $17(68 \%)$ & $\mathbf{n}(\%)$ & $6(24 \%)$ \\
\hline $\begin{array}{l}\text { Teaching and learning } \\
\text { Healthy school policy }\end{array}$ & $1(4 \%)$ & - & $25(100 \%)$ \\
\hline $\begin{array}{l}\text { Partnerships and } \\
\text { services }\end{array}$ & $7(28 \%)$ & $17(68 \%)$ & $7(28 \%)$ \\
\hline
\end{tabular}

Abbreviation: CSH, comprehensive school health.
All secondary schools in Time II $(\mathrm{n}=17)$ reported hosting activities during the lunch hour. Examples of activities included a skit entitled "Fruit Ninja" to raise awareness of the benefits of fruit and vegetable consumption; mini talent shows or open mic events; pep rallies; and competitions to win P/PM 150-compatible food prizes (i.e. "minute-to-win it," "rap for a wrap," "sing for a salad," and healthy eating quizzes). No such activities were identified in elementary schools as representatives reported that lunch time was dedicated to eating and socializing, followed by an outdoor recess.

\section{Teaching and learning}

School support for healthy eating within the teaching and learning pillar was exemplified in Time II through activities such as offering media literacy instruction on special topics related to healthy eating ( $80 \%)$, field trips to farmers' markets (40\%) and field trips to the local grocery store $(32 \%)$. Additionally, the FES indicated $80 \%$ of schools offered ad hoc gardening opportunities to students in select gardens, such as tending the school's memorial or peace garden, planting an herb garden or discussing gardening in the school's Eco Club. Support for the development of students' food skills was demonstrated in many schools (60\%) through hospitality classes and participation in regional food education days and region-wide specialty snack days.

Many schools offered regular breakfast programs $(44 \%, n=11)$, lunch programs $(12 \%, \mathrm{n}=3)$ and/or snack programs $(8 \%, n=2)$. A majority of breakfast programs $(77 \%, \mathrm{n}=10)$ were made available to all students for no fee and provided services an average of three days a week (range $=1-5$ days). Lunch programs ran one, four, or five days a week; however, universally available lunch programs (regardless of ability to pay) occurred in only one of three schools. The snack programs $(n=2)$ were free to all students, and ran either once or three times a week. All nutrition programs were reviewed by school administration at least once per year and, being offered free of charge, did not operate under P/PM 150 jurisdiction and as such, were exempt from its standards.

At Time II, several school representatives reported not needing a breakfast program (32\%), lunch program $(48 \%)$, and/or a 
snack program (52\%). Reasons for not requiring a nutrition program included not identifying a need (i.e. students always came to school with lunch, high socioeconomic status neighbourhood). In contrast, for some schools that did not have nutrition programs in Time I or Time II, representatives reported that a breakfast $(16 \%)$, lunch $(32 \%)$ or snack program $(12 \%)$ was desired to help address, for example, poor dietary habits witnessed by teachers in classrooms and cafeterias. To initiate such a program, representatives identified a need for additional funding and volunteers.

\section{Healthy school policy}

This pillar was well supported in both time periods by many schools $(64 \%$; Table 4). To support healthy eating through policy outside of P/PM 150, schools ensured that healthy food choices were available at reasonable or subsidized prices $(24 \%$ written policies; $32 \%$ formal practices); the use of sugary treats as rewards in the classroom were avoided ( $8 \%$ written policies; $48 \%$ formal practices); and foods sold through off-campus fundraisers were healthy $(16 \%$ written policies; $12 \%$ formal practices). Examples of non-food fundraisers from the FES included sales of magazines, cookware, flowers and plants and special events such as movie nights, student dances, skating field trips and carwashes.

All participating elementary schools had a written policy restricting students from leaving school property without a written note from a parent or guardian, which is helpful in restricting access to local food outlets. For both elementary and secondary schools, the FES identified the number of P/PM 150 exemption days used. No school reported surpassing the 10-day limit (average $=3$, range $=0-10$ days/ year) in either time period. Exemption days were used for school barbecues, onsite fundraisers (e.g. bake sales, "candy grams"), and curriculum-related events (e.g. French café, business venture competition).

\section{Partnerships and services}

The partnerships and services pillar had variable levels of support across schools (Table 4). As demonstrated by Time II data, schools that had high/increased support for the partnerships and services pillar often provided school staff with in-service training on topics such as nutrition (44\%), teaching a healthy eating curriculum (32\%) and promoting positive body image $(28 \%)$. In Time I, when P/PM 150 was first mandated, the majority of schools (88\%) sent a school representative to receive formal training provided by the regional public health unit in partnership with the affiliated school boards. In addition, many schools opted for a consultation with their school PHN (68\%) and/or school board-funded P/PM 150 coordinator $(56 \%)$ to help implement the policy in the local setting. In Time II, only $20 \%$ of schools met with a PHN, and the school boards' P/PM 150 coordinators had been discontinued. Some schools received $\mathrm{P} / \mathrm{PM}$ 150-related resources in Time II, including written $(24 \%)$ and/or electronic (20\%) resources relevant to healthy eating, nutrition or policy.

Even though most school representatives did not meet to discuss P/PM 150 with a PHN in Time II, the regional public health unit shared resources and information with school staff (88\%), helped develop and implement programs (60\%) and/or assisted in problem solving (32\%). In the broader community, schools reported working on healthy eating promotion and activities for students with community health organizations (e.g. Heart and Stroke Foundation, Canadian Cancer Society; $32 \%)$, the school board (28\%), the municipal parks and recreation department (24\%), a youth organization (e.g. YMCA, Boys and Girls Club; 16\%), and/or a health and fitness club (12\%). Over the course of Time II, four schools reported having no contact with their regional public health unit, and five other schools reported not establishing external community connections to support healthy eating.

\section{Discussion}

Having supports in place across CSH pillars during policy implementation has been shown to be effective at fostering positive student health behaviours. ${ }^{2,29}$ Our study showed variable levels of support for CSH pillars during mandated School Food and Beverage Policy (P/PM 150) implementation across schools in two time periods. For example, all schools achieved a high level of support for the physical environment pillar for both time periods because of Ontario's commitment to the provision of safe, supportive physical school environments in line with recommendations set by the WHO. ${ }^{30}$ In contrast, the social environment pillar received the lowest ratings, perhaps due to the need for extracurricular initiatives to be driven by individuals at the school level.

The school principal is a gatekeeper with the power to facilitate or restrict the adoption, implementation and sustainability of CSH initiatives. ${ }^{9,20,22,31-34}$ Individuals with a personal passion for improving the health behaviours of students, referred to as school health champions, are key facilitators to ongoing support of $\mathrm{CSH}$ initiatives within and external to the classroom..$^{20,21,35,36}$ In our study, school health champions were teachers who dedicated their non-classroom time (i.e. lunch breaks, after school) to run programs and supervise students in nutrition action councils, eco clubs, or extracurricular food skills competitions. Open-ended responses from school representatives linked champions to the few initiatives within the low-rated social environment pillar.

Supporting champions has required the provision of dedicated, paid time for program planning and/or hiring an external coordinator to champion program development and implementation alongside school stakeholders. ${ }^{18,19,21-23}$ When stakeholders, be they teachers, school staff, food service providers, families, community partners, health promotion officials or students, are engaged in the decisionmaking process, there is an increased sense of buy-in and ownership that leads to a personal commitment to sustain $\mathrm{CSH}$ initiative outcomes. ${ }^{19,22,23,37,38}$ In our study, school staff members said they were not often consulted on discussions related to healthy eating in their schools, and one may assume this disengagement may have contributed to a lack of extracurricular supports for healthy eating within the social environment pillar. Future work is needed to include staff in such discussions to further build buy-in for healthy eating promotion in schools and, perhaps, to help encourage the uptake of P/PM 150 standards.

Schools in our study demonstrated various levels of stakeholder involvement; however, actions such as engaging community members in discussions about healthy eating and supporting existing partnerships with external organizations were both associated with improvements within CSH pillars and between Time I and Time II. For example, a participating 
secondary school connected with local health-related organizations to host a week of wellness events including fitness classes, cooking lessons and health promotion seminars to support the new $\mathrm{P} / \mathrm{PM}$ 150 and reinforce positive healthy living behaviours. Previous studies have demonstrated that successful partnerships lead to increased availability of supports, resources and opportunities for promoting healthy eating messages to be reinforced in public spaces, external to the school, where children live, learn and play. ${ }^{18-20,39}$

The formation of partnerships can be challenging, and sometimes there is little benefit for schools. ${ }^{9,18,40}$ This may explain why schools in our study experienced low levels of support in the partnerships and services pillar; five schools did not establish connections with external partners and four schools did not contact their school PHN in the previous school year. The literature reports some school officials may avoid involving stakeholder groups because "it is faster to be directive than work collaboratively." ${ }^{41, p .524}$

Sometimes approaching stakeholders can be met with resistance. For example, food service workers may approach healthy eating strategies from a business perspective as opposed to a health promotion stance, or parents may not agree with the health promotion messages or may not be able to reinforce teachings at home due to issues regarding food insecurity, cultural norms or personal health beliefs. ${ }^{20,38}$ Future qualitative research is needed to better understand the barriers to forming and sustaining community partners in support of healthy school food environments.

Another barrier to CSH implementation is the lack of available funding. Historically, when schools have been provided with external funding, representatives have been able to implement CSH components based upon the priorities of the school community. ${ }^{9,19,20}$ Conversely, without supplementary funds, school staff have previously reported not being able to engage in $\mathrm{CSH}$ initiatives because they were not compensated for their time. ${ }^{20,21,38,39}$ We found that the availability of funds from government grants, external fundraising and/or student payment made it possible for some schools to offer regular free or subsidized breakfast, lunch or snack programs. In some cases though, those who wished to have student nutrition programs were limited by a lack of funds.

When funds were available to a school from external non-government sources (the only sources available during the course of this study), students took part in skill-development activities, such as gardening and cooking, as tools and materials (e.g. plants, cookware, ingredients) could be afforded. Two elementary schools in our study sourced funding and food from a local grocery store, to host nutrition education sessions for students and parents. They garnered further support from school PHNs who were educated in healthy eating promotion and willing to help with grant applications. More work is needed to raise the awareness of school officials of funding opportunities that may help address the unique needs of school communities.

Context plays a significant role in the successful implementation of CSH initiatives. When implementation strategies account for context, schools are able to align priorities with $\mathrm{CSH}$ policy.9,18,20,22,41,42 For example, the Alberta Project Promoting active Living and healthy Eating in Schools (APPLE Schools) aimed to embed wellness into school culture through ongoing events and activities and by including wellness teachings in curriculum. ${ }^{43}$ Through allocated funding, each school was able to dedicate time for staff to connect with a school health facilitator and prioritize school wellness policies and practices. ${ }^{22}$ When school principals had a firm understanding of the project philosophy and recognized its alignment with the priorities of the school, APPLE Schools' $\mathrm{CSH}$ initiatives were successfully implemented and sustained. ${ }^{22}$ The data collected from the current study, related to the dynamic context of schools, emphasizes the need for multiple representatives from positions of power (i.e. Ministry of Education, school board, school principal, school champion) to work with school stakeholders to strategize ways to continue to support healthy eating in all aspects of the CSH framework.

\section{Strengths and limitations}

To the best of our knowledge, this study is one of the first studies to measure the $\mathrm{CSH}$ pillars during P/PM 150 implementation, which adds to the current understanding of Ontario schools' support for healthy eating. Further research can build upon the current findings to examine a doseresponse relationship between the presence of healthy eating support and population-level health outcomes within and between schools.

This study, however, is not without limitations. The relatively low response rate could be attributable to competing priorities within schools or a teacher work-torule political action undertaken during Time I (2012/13) of this study, which restricted researcher contact with school administrators. In five cases, school representatives changed between time periods, providing different perspectives over the course of the data collection timeframes. Furthermore, there may have been selfreport bias, meaning representatives involved with healthy eating practices in the school may have reported outcomes differently from someone less engaged. In addition, the results of this study only provide a snapshot of schools' healthy eating environments, as repeated measures were not obtained across the school year. Since not all the invited schools participated, there is the potential for volunteer bias.

Finally, the CSH framework is exclusive to the school environment and does not consider the external environment, such as the work-to-rule action; the amount and type of competitive foods external to the school; media emphasis on the importance of healthy eating; and other environmental influences from home or recreation centres that may have influenced student healthy eating behaviours.

\section{Conclusion}

Policy is a critical component of CSH initiatives as it provides the top-down support and continued reinforcement needed to sustain individuals' behaviour change. ${ }^{7,8}$ When mandated by an authoritative body, health policies can also help school communities set standards and priorities for other CSH initiatives. ${ }^{43,44}$ This requires additional comprehensive, integrative bottom-up approaches to personally motivate the agents of change (i.e. principals, teachers, staff, community members, parents, students) to adopt and maintain $\mathrm{CSH}$ priorities. $^{45,46}$ These strategies must be orchestrated and coherent, with an implementation strategy that targets several dimensions of student health and the food environment simultaneously. ${ }^{47}$ Without structured assistance throughout the 
implementation process, CSH initiatives will falter. ${ }^{23}$ Results of meta-analyses have demonstrated that effective implementation strategies lead to better outcomes. ${ }^{46}$ Therefore, schools need to develop a structured implementation plan for healthy school policy-one that takes into consideration the unique priorities of the school (social environments), the physical structure (physical environment), the alignment with curriculum and academic achievement goals (teaching and learning), support by existing written policies and informal practices (healthy school policy), and sustainable supports and resources that can be garnered by school and community partners (partnerships and services).

There is at present a real opportunity to apply the lessons learned through this research, as the Ontario Ministry of Education seeks to engage school community members in the recently executed Ontario's Well-Being Strategy for Education. ${ }^{48}$ This initiative aims to better understand the physical, cognitive, emotional and social well-being of children and build upon the current system to support all aspects of children's health and development. We recommend that the Ontario Ministry of Education, community partners and school officials consider using the $\mathrm{CSH}$ framework to better understand how well-being, such as student eating behaviours, are impacted by all aspects of the school environment. Furthermore, tools such as the Healthy School Planner can help the Ministry and school communities learn about activities that are working well, as well as those needing further support.

\section{Acknowledgements}

This manuscript includes data from the Healthy School Planner (HSP). This tool was developed by the Pan-Canadian Joint Consortium for School Health in partnership with the Propel Centre for Population Health Impact, University of Waterloo. The HSP research was supported by Canadian Cancer Society grant \#2011701019. Authors were supported by the Canadian Institutes of Health Research Training Grant in Population Intervention for Chronic Disease Prevention, and the Region of Peel Public Health.

\section{Conflicts of interest}

The authors have no conflicts of interest to declare.

\section{Authors' contributions}

TO contributed to all aspects of this research, including research design, tool development, data collection, analysis, manuscript writing and approval of the final version. RC and SM contributed to research design, tool development, overseeing data collection and analysis, as well as approval of the final manuscript.

\section{References}

1. Aldinger CE, Jones JT. Healthy nutrition: an essential element of a health-promoting school [Internet]. Geneva (CH): World Health Organization; 1998 [cited 2014 Sep]. [WHO information series on school health: document four]. Available from: http://www.who.int/school_youth _health/media/en/428.pdf?ua = 1

2. Diressen CE, Cameron AJ, Thornton LE, Lai SK, Barnett LM. Effect of changes to the school food environment on eating behaviours and/or body weight in children: a systematic review. Obes Rev. 2014;15(12):968-82.

3. Story M, Kaphingst KM, French S. The role of schools in obesity prevention. Future Child. 2006;16:109-42.

4. Healthy Kids Panel. No time to wait: the Healthy Kids Strategy. Toronto (ON): Queen's Printer for Ontario; [2013 Feb; cited 2014 Sep 2014]. [Catalogue No.: 017308]. Available from: http://c.ymcdn.com/sites/www .alphaweb.org/resource/collection / 822 EC60D-0D03-413 E-B 590 - AFE1AA8620A9/HKP_FINAL _English_Report_130221.pdf

5. Public Health Agency of Canada. Supportive environments for learning: healthy eating and physical activity within comprehensive school health. Can J Public Health. 2010; 101(Suppl 2):S1-S32.

6. World Health Organization (WHO). Global strategy on diet, physical activity and health: childhood overweight and obesity [Internet]. Geneva $(\mathrm{CH})$ : WHO; [2014; cited 2014 Sep]. Available from: http://www.who.int /dietphysicalactivity/childhood/en/

7. Ardzejweska K, Tadros R, Baxter D. A descriptive study on the barriers and facilitators to implementation of the NSW (Australia) Healthy School Canteen Strategy. Health Educ J. 2012;72(2):136-45.
8. Gleddie DL. The devil is in the details: development of policy and procedure in the Battle River Project. Health Educ J. 2010;71(1):30-8.

9. Inchley J, Muldoon J, Currie C. Becoming a health promoting school: evaluating the process of effective implementation in Scotland. Health Promot Int. 2007;22(1):65-71.

10. Ontario Ministry of Education. Policy/ Program Memorandum No. 150. School food and beverage policy [Internet]. Toronto (ON): Queen's Printer for Ontario; [modified 2010 Oct 4; cited 2014 Sep]. Available from http:// www.edu.gov.on.ca/extra/eng/ppm /150.html

11. Chaleunsouk L, Kutsyuruba B. Ontario schools' readiness for School Food and Beverage Policy implementation. J Educ Policies Curr Pract. 2014;1(1): 13-29.

12. Vine M, Elliott SJ. Examining locallevel factors shaping school nutrition policy implementation in Ontario, Canada. Public Health Nutr. 2014;17(6): 1290-8.

13. Vine MM, Elliott SJ, Raine KD. Exploring implementation of the Ontario School Food and Beverage Policy at the secondary-school level: a qualitative study. Can J Diet Pract Res. 2014; 75(3):118-24. doi: 10.3148/cjdpr-2014 -003 .

14. Rideout K, Levy-Milne R, Martin C, Ostry AS. Food sales outlets, food availability, and the extent of nutrition policy implementation in schools in British Columbia. Can J Public Health. 2007;98(4):246-50.

15. Samuels SE, Hutchinson KS, Craypo L, Barry J, Bullock SL. Implementation of California state school competitive food and beverage standards. J Sch Health. 2010;80(12):581-7.

16. Fung C, Kuhle S, Lu C, et al. From "best practice" to "next practice": the effectiveness of school-based health promotion in improving healthy eating and physical activity and preventing childhood obesity. Int J Behav Nutr Phys Act [Internet]. 2012 [cited 2014 Sep];9:27. Available from: http://dx.doi.org/10.1186/1479-5868 $-9-27$ 
17. Fung C, McIsaac JLD, Kuhle S, Kirk SFL, Veugelers PJ. The impact of a population-level school food and nutrition policy on dietary intake and body weights of Canadian children. Prev Med. 2013;57(6):934-40.

18. Deschesnes M, Martin C, Jomphe Hill A. Comprehensive approaches to school health promotion: how to achieve broader implementation? Health Promot Int. 2003;18(4):387-96.

19. Gleddie DL, Hobin EP. The Battle River Project: school division implementation of the health-promoting schools approach: assessment for learning: using student health and school capacity measures to inform action and direct policy in a local school district. Glob Health Promot. 2011:18(1):39-42.

20. McIsaac JLD, Read K, Veugelers PJ, Kirk SFL. Culture matters: a case of school health promotion in Canada. Health Promot Int. 2017;32(2):207-17. doi:10.1093/heapro/dat055.

21. Rasberry CN, Slade S, Lohrmann DK, Valois RF. Lessons learned from the whole child and coordinated school health approaches. J Sch Health. 2015; 85(11):759-65.

22. Roberts E, McLeod N, Montemurro G, Veugelers PJ, Gleddie D, Storey, KE. Implementing comprehensive school health in Alberta: the principal's role. Health Promot Int. 2016;31(4):915-24. doi: 10.1093/heapro/dav083.

23. Senior E. Becoming a health promotion school: key components of planning. Glob Health Promot. 2012;19(1):23-31.

24. Veugelers PJ, Schwartz ME. Comprehensive school health in Canada. Can J Pub Health. 2010;101(Suppl 2):S5-S8.

25. Pan-Canadian Joint Consortium for School Health. Comprehensive School Health Framework: what is comprehensive school health? Summerside (PEI): Joint Consortium for School Health; 2015 [2014 Sep]. Available from: http:// www.jcsh-cces.ca/index.php/about /comprehensive-school-health

26. Healthy School Planner Survey. Background information from the Joint Consortium for School Health Survey. Waterloo (ON): Pan-Canadian Joint Consortium for School Health; 2013. Available from: http://hsp.uwaterloo .ca/
27. Accreditation Canada. Pan-Canadian Joint Consortium for School Health (JCSH) Healthy School Planner [Internet]. Ottawa (ON): Accreditation Canada; 2017 [cited 2017 Jun]. Available from: https://accreditation.ca/pan-canadian -joint-consortium-school-health-jcsh -healthy-school-planner

28. Habayeb D. Evaluating implementation of the Ontario School Food and Beverage Policy (P/PM 150) in Waterloo region: role of food services [unpublished master's thesis]. [Waterloo (ON)]: University of Waterloo; 2013. 137 p.

29. Langford R, Bonnell CP, Jones HE, et al. The WHO Health Promoting School framework for improving the health and well-being of students and their academic achievement. Cochrane Database Syst Rev. 2014;(4):CD008958. DOI: 10.1002/14651858.CD008958.pub2.

30. Wargo J. The physical school environment: an essential component of a health-promoting school.. Geneva $(\mathrm{CH})$ : World Health Organization; 2004. [WHO Information Series on School Health Doc. No. 2]. 257 p.

31. Fullan MG. Successful school improvement: the implementation perspective and beyond. Philadelphia (PA): Open University Press; 1992.

32. Rohrbach LA, Graham JW, Hansen WB. Diffusion of a school-based substance abuse prevention program: predictors of program implementation. Prev Med. 1993;22(2):237-60.

33. Storey KE, Spitters H, Cunningham C, Schwartz M, Veugelers PJ. Implementing comprehensive school health: teachers' perceptions of the Alberta Project Promoting active Living and healthy Eating in Schools - APPLE schools. PHEnex J [Internet]. 2011 Jul [cited 2014 Sep];3(2)1-18. Available from: http://ojs.acadiau.ca/index.php /phenex/article/view/1422

34. Storey KE. Implementing comprehensive school health: from 'doing' to 'facilitating.' Paper presented at: Ever Active Schools, 4th annual Shaping the Future Conference; 2013 Jan 24-26; Kananaskis, Alberta, Canada.

35. Stolp S, Wilkins E, Raine KD. Developing and sustaining a healthy school community: essential elements identified by school health champions. Health Educ J. 2014;74(3):299-311.
36. Valois RF, Lewallen TL, Slade S, Tasco A. The ASCD healthy school communities projects: formative evaluation results. Health Educ. 2015;115(3/4): 269-84.

37. O’Hara J, McNamara G. Process and product issues in the evaluation of school development planning. Evaluation. 2001;7(1):99-109.

38. Lucarelli JF, Alaimo K, Mang E, et al. Facilitators to promoting health in schools: is school health climate the key? J Sch Health. 2014;84(2):133-40.

39. Holosko MJ, Dunlop JM. Evaluating interorganizational approaches to service delivery: a case example of the family violence serve project in Kent county, Ontario. Can J Program Eval. 1992;7(2):115-29.

40. Marshall BJ, Sheehan MM, Northfield JR, Maher S, Carlisle R, St. Leger LH. School-based health promotion across Australia. J Sch Health. 2000;70(6): 251-2.

41. Rowling L. The adaptability of the health promoting schools concept: a case from Australia. Health Edu Res. 1996;11(4):519-26.

42. St. Leger L. Schools, health literacy and public health: possibilities and challenges. Health Promot Int. 2001; 16(2):197-205.

43. Sabatier PA. Top-down and bottom-up approaches to implementation research. In: Hill M, editor. The policy process: a reader. 2nd ed. New York (NY): Harvester Wheatsheaf; 1997:267-93.

44. Tang KC, Nutbeam D, Aldinger C, et al. Schools for health, education and development: a call for action. Health Promot Int. 2009;24(1):68-77.

45. Gleddie DL, Melnychuck NE. An introduction to the Battle River Project: district implementation of a health promoting schools approach. Phys Health Educ J. 2009;75(2):24-31.

46. Durlak JA, DuPre EP. Implementation matters: a review of research on the influence of implementation on program outcomes and the factors affecting implementation. Am J Community Psychol. 2008;41(3-4):327-50. 
47. Allensworth DD, Kolbe LJ. The comprehensive school health program: exploring an expanded concept. J Sch Health. 1987;57(10):409-12.

48. Ontario Ministry of Education. Promoting Well-Being in Ontario's Education System [Internet]. [2016 May 4; cited 2017 Jan 22]. Available from: http://www.edu.gov.on.ca/eng /about/wellbeing2.html 